\title{
SABERES E PRÁTICAS DOCENTES E ENSINO DE HISTÓRIA: TEMAS, CONCEITOS E REFERENCIAIS (1970-2014)
}

\author{
Nadia Gaiofatto Gonçalves* \\ Universidade Federal do Paraná (UFPR), Curitiba - PR, Brasil \\ Ana Maria Ferreira da Costa Monteiro** \\ Universidade Federal do Rio de Janeiro (UFRJ), Rio de Janeiro - RJ, Brasil
}

RESUM0: Este trabalho visa analisar a produção acadêmica sobre Saberes e Práticas Docentes relacionadas ao Ensino de História, presente em periódicos acadêmicos das áreas de Educação, Ensino e História, no período de 1970 a 2014, buscando-se evidenciar temas, conceitos e referenciais contemplados. Como principais referenciais, utilizam-se os conceitos de habitus e campo, de Pierre Bourdieu, e de representações e lutas de representações, de Roger Chartier. Como principais resultados, destacam-se a grande concentração da produção a partir do século XXI; a coincidência de aumento de artigos com a produção específica de saberes e práticas docentes no Brasil; a presença de conceitos relacionados a saberes e práticas docentes em significativa parte da produção, mas também artigos sem a explicitação de conceitos específicos a essa problematização; e a luta de representações que se desenha, com a entrada de trabalhos relacionados à perspectiva da Educação Histórica, para abordagem da temática no campo Ensino de História.

Palavras-chave: Ensino de História. Saberes e práticas docentes. Estado da arte. Periódicos acadêmicos. Campo acadêmico.

\section{TEACHING KNOWLEDGE AND PRACTICE AND THE TEACHING OF HISTORY: THEMES, CONCEPTS AND REFERENCES (1970-2014)}

ABSTRACT: The aim of this study is to analyze academic production on teaching practices and knowledge concerning the teaching of History in academic journals in the fields of Education, Teaching and History from 1970 to 2014, seeking evidence of the themes, concepts and references under study. The main benchmarks are the concepts of habitus and field of

http://dx.doi.org/10.1590/0102-4698156257

Elocation-id - e 156257

"Doutora em Educação, Docente da Universidade Federal do Paraná. Grupos de Pesquisa: Laboratório de Estudos e Pesquisas em Ensino de História; Núcleo de Estudos e Pesquisas em História da Formação e das Práticas Educativas. E-mail: < nadiagg@ufpr.br >.

"“Doutora em Educação, Docente da Universidade Federal do Rio de Janeiro. Grupos de pesquisa: Laboratório de Estudos e Pesquisas em Ensino de História (líder), Núcleo de Estudos de Currículo e Oficinas da História. E-mail: < anamont@ufri.br > 
Pierre Bourdieu, and the representations and struggles over representation of Roger Chartier. The main results include the high concentration of academic production from the twenty-first century and the coincidence of the growing number of articles with the specific production of teaching practice and knowledge in Brazil. Another result is the presence of concepts related to knowledge and teaching practices in a significant part of the production, but also articles with no concepts specifically addressing this problematization and the struggle over representations that is arising with the entry of works related to the perspective of Historical Education to address the theme in the field of teaching History.

Keywords: History teaching. Teaching knowledge and practices. State of the art. Academic journals. Academic field.

\section{INTRODUCุ̃̃O}

Este trabalho é parte de uma pesquisa que tem por objetivo analisar como o Ensino de História foi abordado em periódicos acadêmicos de Educação, Ensino e História, desde os anos de 1970. No recorte aqui apresentado, o foco está nos artigos que discutem saberes e práticas docentes relacionados ao Ensino de História.

Identificando tendências, divergências, consensos, movimentos na produção acadêmica, busca-se compreender com mais clareza perspectivas, limitações, contribuições e demandas de pesquisa sobre o tema, além de lutas de representações que as perpassam. Apesar de sua abrangência e da diversidade de concepções, métodos e abordagens metodológicas envolvidas nessas produções, assume-se, aqui, o pressuposto de existência, no Brasil, de um "campo específico do ensino de História” (SCHMIDT, 2012, p. 76), para o qual se volta essa investigação.

Assume-se, aqui, uma concepção ampla de saberes e práticas, como "as formas com que professores de História mobilizam os saberes que dominam para lidar com os saberes que ensinam, formas essas nas quais são articulados saberes disciplinares, saberes curriculares, saberes pedagógicos e saberes da experiência, numa criação própria e significativa para seus alunos" (MONTEIRO, 2007, p. 14), que, por sua vez, orientam as práticas para propiciar o ensino da disciplina.

O início dos anos de 1970, que demarca no Brasil o momento de criação e consolidação de programas de pós-graduação e de periódicos acadêmicos, foi a referência temporal inicial desta pesquisa, que abrangeu produções acadêmicas publicadas em periódicos brasileiros, até o ano de 2014 . 
Esse recorte inicial está relacionado à proposta de periodização da história do Ensino de História no Brasil, apresentada por Schmidt (2012), que, com base no conceito de código disciplinar, propõe quatro períodos mais marcantes nessa produção: "construção do código disciplinar da história no Brasil (1838-1931); consolidação do código disciplinar da história no Brasil (1931-1971); crise do código disciplinar da história no Brasil (1971-1984); reconstrução do código disciplinar da história no Brasil (1984-?)" (SCHMIDT, 2012, p. 78). Para a autora, o que demarca os dois últimos períodos são, respectivamente, a Lei 5692/71 e seu impacto no Ensino de História, em especial, a imposição dos Estudos Sociais como matéria; e um movimento de "volta ao ensino de História", após a ditadura, com a busca de novos referenciais.

Desses contextos derivaram produções acadêmicas a respeito do tema, que serão analisadas no decorrer da pesquisa, na qual também será averiguado, de certa forma, o diálogo dessas produções em relação à historiografia, por meio dos conceitos de campo e habitus de Bourdieu, em especial suas problematizações relativas ao campo científico, e representações e luta de representações de Chartier, como será explicitado adiante.

Sobre esse tipo de pesquisa, chamada de estado da arte ou estado do conhecimento, Barreto e Pinto (2001, p. 5) destacam:

O balanço do conhecimento produzido sobre um tema permite que se organize o conjunto de informações disponíveis, com vista a identificar tendências e recorrências, indicar as possibilidades de integração de diferentes perspectivas e localizar lacunas e questões emergentes.

\section{FONTES E PROCEDIMENTOS METODOLÓGICOS}

A fim de realizar os objetivos e a análise proposta nesta investigação, a fonte de pesquisa foram periódicos acadêmicos nacionais, constantes no Qualis - CAPES, com classificação mínima entre A1 e B3, das áreas de Educação, História e Ensino, com objeto que permitisse a inserção de artigos sobre Ensino de História.

Optou-se por periódicos acadêmicos por considerar a abrangência que tal fonte oferece e porque minimizam as restrições e maximizam as vantagens que Sirinelli (1996, p. 249) ressalta:

As revistas conferem uma estrutura ao campo intelectual por meio de forças antagônicas de adesão - pelas amizades que as subtendem, as fidelidades que arrebanham e a influência que exercem - e de exclusão - pelas posições tomadas, os debates suscitados, e as cisões advindas. [...] elas são aliás um lugar precioso para 
a análise do movimento das idéias. Em suma, uma revista é antes de tudo um lugar de fermentação intelectual e de relação afetiva, ao mesmo tempo viveiro e espaço de sociabilidade, e pode ser, entre outras abordagens, estudada nesta dupla dimensão.

Ainda sobre as publicações periódicas, Corrêa (1999, p. 11) destaca como essa fonte tem sido alvo de atenção de pesquisadores interessados na produção intelectual de determinados períodos da história: "Por suas características próprias, essas publicações sequenciais podem proporcionar ao estudioso as possibilidades de vislumbrar quais os temas de interesse na época, a maneira como foram abordados, quem eram seus autores".

Segundo Prost (1996, p. 315), se o pesquisador quer que apareçam "contrastes entre grupos e/ou entre períodos, deve constituir seus corpus de textos comparáveis, distribuídos por várias datas e/ou emanando de vários locutores que possa considerar como representativos". Nesse sentido, os procedimentos metodológicos foram desenvolvidos a partir da perspectiva de Prost (1996, p. 323), que ressalta a necessidade de três características básicas quanto ao corpus ${ }^{1}$ :

[...] ser contrastivo para permitir comparações, ser diacrônico, ou seja, estender-se no tempo para permitir recuperar continuidades e viradas; (e) enfim, ser constituído, senão de textos de organizações que emanam de locutores coletivos, ao menos de textos significativos, referentes a situações de comunicação determinadas.

Além disso, a escolha por periódicos deve-se à compreensão de que a divulgação das pesquisas faz parte do processo de construção do conhecimento, em um contínuo diálogo coletivo, o que pode ser feito de maneira mais ampla, por meio dos periódicos.

Foram aplicados os seguintes filtros na listagem geral de periódicos Qualis²: seleção dos periódicos das áreas de Educação, História e Ensino; exclusão de periódicos internacionais; exclusão de periódicos nacionais cujo objeto específico não abrangeria o tema Ensino de História ${ }^{3}$; seleção de periódicos que estivessem indicados como relevantes (A1 a B3) para ao menos duas áreas das três contempladas na pesquisa. Em um primeiro momento, desses filtros, resultou uma relação inicial de 164 ISSN, que foram averiguados na íntegra de suas publicações no período ${ }^{4}$, à busca de artigos relacionados ao tema Ensino de História. Durante a consulta, foram excluídos outros, identificados como internacionais ou com objeto incompatível, resultando em uma listagem que contempla 130 ISSN, ou 95 periódicos ${ }^{5}$.

A seleção dos artigos foi feita com base no título, nas palavraschave e no resumo, a partir do critério de que o trabalho deveria ter foco central no Ensino de História, independente do problema colocado, da abordagem, do recorte ou do referencial escolhido ${ }^{6}$. 
Quanto à organização do material selecionado, ressaltase que toda classificação implica uma leitura e análise das autoras sobre os textos. Assim, a ênfase da leitura foi identificar como o tema foi abordado naquela produção acadêmica. A organização das informações dos trabalhos foi feita a partir dos seguintes elementos: periódico - ano de criação, estado e instituição de vínculo; referência; local (físico ou site) em que está disponível; ano de publicação; instituição(ões) de vínculo dos autores; natureza do texto (ensaio ou pesquisa); abordagem (histórica ou contemporânea à publicação); eixos temáticos (foco do trabalho); conceitos ou categorias principais; referenciais: principais autores utilizados; fontes utilizadas.

\section{REFERENCIAIS}

Para a abordagem do problema de pesquisa e orientando o olhar sobre as fontes, foi assumida a acepção de campo, no caso científico, como "O universo no qual estão inseridos os agentes e as instituições que produzem, reproduzem ou difundem [...] a ciência. Esse universo é um mundo social como os outros, mas que obedece a leis sociais mais ou menos específicas" (BOURDIEU, 2004, p. 20).

Cada agente, durante sua trajetória e em seu habitus, incorpora disposições duráveis adquiridas e regras desse campo (BOURDIEU, 1983) - o que, por sua vez, condiciona suas representações sobre o mundo e sobre o próprio campo -, que tem relativa autonomia em relação a pressões externas. Para Bourdieu, as pressões exercidas sobre os agentes derivam, principalmente, das regras do próprio campo, que são mediatizadas pela sua lógica, que, por sua vez, é dinâmica e constituída pelos agentes que a compõem, em relações de força e disputas por legitimidade: "É a estrutura das relações objetivas entre os agentes que determina o que eles podem e não podem fazer. Ou, mais precisamente, é a posição que eles ocupam nessa estrutura que determina ou orienta, pelo menos negativamente, suas tomadas de posição" (BOURDIEU, 2004, p. 23, grifos do autor).

Sob essa perspectiva, os periódicos acadêmicos constituem instrumentos que podem ser utilizados pelos agentes do campo, para o fortalecimento de determinado viés e como orientadores do que não deve ser feito, no sentido de menor aceitação e legitimidade. Seria o caso, por exemplo, de referenciais utilizados ou temas abordados que, em dado momento, são considerados inadequados por parte dos agentes: conforme sua força no campo, essa compreensão pode ser 
imposta por diversos caminhos, como por meio da análise dos artigos submetidos a eventos ou periódicos, seja tanto na maior visibilidade do novo referencial considerado legítimo, quanto na menor exposição de outras perspectivas. Esse movimento pode ocorrer simultaneamente na escolha das referências e das abordagens utilizadas na formação de professores, contribuindo para o fortalecimento da legitimidade de determinada representação sobre o campo e o tema.

\footnotetext{
Essa estrutura é, grosso modo, determinada pela distribuição do capital científico num dado momento. Em outras palavras, os agentes (indivíduos ou instituições) caracterizados pelo volume de seu capital determinam a estrutura do campo em proporção ao seu peso, que depende do peso de todos os outros agentes, isto é, de todo o espaço. Mas, contrariamente, cada agente age sob a pressão da estrutura do espaço que se impõe a ele tanto mais brutalmente quanto seu peso relativo seja mais frágil. Essa pressão estrutural não assume, necessariamente, a forma de uma imposição direta que se exerceria na interação (ordem, influência, etc.). (BOURDIEU, 2004, p. 24)
}

Em consonância com as proposições de Bourdieu, as contribuições de Roger Chartier também serão úteis para esta pesquisa. Chartier (1990) aborda a questão das leituras ou dos entendimentos possíveis a partir da noção de representação, ou as diferentes formas que uma realidade é dada a ler. Segundo ele, as percepções dos sujeitos sociais não são neutras, dependendo do contexto em que foram elaboradas e constituídas, e derivando delas as suas práticas. A visão de mundo constitui o mecanismo de justificativas individuais, que permitem que o indivíduo interaja com o mundo por meio de suas práticas e representações, entendidas aqui como as diversas formas como a realidade pode ser interpretada, e que se expressa na vida prática.

Nesta pesquisa, assume-se que as produções acadêmicas são utilizadas e exercem influência nas representações e no babitus dos agentes, tanto do campo acadêmico, contribuindo para novas pesquisas, publicações, apresentações de trabalhos, indicações de leituras para estudantes, ou seja, na sua difusão e consolidação, quanto em outros campos, como o escolar, na medida em que há um poder simbólico em operação no reconhecimento de autoridade do campo acadêmico e das produções dele derivadas.

\section{RESULTADOS INICIAIS DA PESQUISA: CARACTERIZAC̣ÃO DOS PERIÓDICOS E DOS ARTIGOS}

Dos 95 periódicos pesquisados, 69 foram localizados na íntegra de seus números, nos quais foram identificados artigos sobre o tema; 17 ainda encontram-se em busca de números impressos esparsos 
(sendo que em 14 deles já há artigos identificados); e em 09, foi feita a pesquisa na íntegra, mas nenhum artigo sobre o tema foi localizado.

A pesquisa nos periódicos foi realizada primeiramente com busca na internet, nos sites dos periódicos. Todos os artigos selecionados naquele momento tiveram seus arquivos copiados utilizando-se a sigla designada para o periódico, o ano do trabalho e o sobrenome do autor - por exemplo, AE2012silva - para facilitar, posteriormente, o acesso, a leitura e a análise dos mesmos.

Esgotada a pesquisa na internet, passou-se à busca em bibliotecas. Nessa fase está a parte mais antiga dessa produção, o que justifica a dificuldade de se encontrarem alguns números iniciais dos periódicos. Até este momento, estima-se que cerca de 68 volumes do total a ser pesquisado ainda não foram localizados, o que corresponde a 1,65\% do total.

Foram pesquisados os acervos das bibliotecas da Universidade Federal do Paraná, da Universidade Federal do Rio de Janeiro, da Universidade Estadual do Rio de Janeiro, da Biblioteca Nacional, da Universidade Estadual Júlio de Mesquita Filho - Unesp - Campus Assis, da Universidade Estadual de Maringá, da Universidade Tuiuti do Paraná, da Pontifícia Universidade Católica do Paraná e, ainda, da Universidade de São $\mathrm{Paulo}^{7}$ - Faculdade de Educação.

Quanto à criação, ou ao início das publicações desses periódicos, $62 \%$ tiveram início nos últimos 25 anos, o que pode ser decorrência tanto da consolidação dos programas de pós-graduação no país, quanto das crescentes exigências estabelecidas pela CAPES aos pesquisadores, em especial docentes vinculados a esses programas. De acordo com Cirani, Campanário e Silva (2005), a partir de dados da Capes, é visível a grande expansão dos programas de pósgraduação no Brasil, desde o fim dos anos de 1990. Eles "somavam 2.417 em 1999 para atingir um total de 4.660 em 2011, praticamente dobrando o número de cursos. Os cursos de doutorado, em 1999, contabilizavam 800 e, em 2011, somam 1.606, dobrando o número" (CIRANI; CAMPANÁRIO; SILVA, 2015, p. 169). Em relação aos cursos de mestrado, vão de 1.589, em 1999, para 2.725, em 2011.

Em relação aos estados em que os periódicos são produzidos, há grande concentração destes na região Sudeste (48, ou 50,5\%) e Sul (33, ou 34,7\%). Considerando-se as instituições que produzem os periódicos, a maioria é publicada por Instituições de Ensino Superior (IES) públicas, em geral universidades, correspondendo a $63 \%$ das revistas, seguida pelas IES particulares, confessionais ou filantrópicas $(20,8 \%){ }^{8}$

Dos 95 periódicos pesquisados, foram localizados e analisados 4.123 volumes. ${ }^{9}$ Destes, não foram encontrados artigos em 3.753, ou seja, em 368 deles, houve artigos sobre Ensino de História 
localizados. ${ }^{10}$ Foram localizados até o momento 876 artigos. A sua distribuição temporal pode ser observada no Gráfico 1.

GRÁFICO 1 - Ensino de História - Artigos por período (1970-2014)

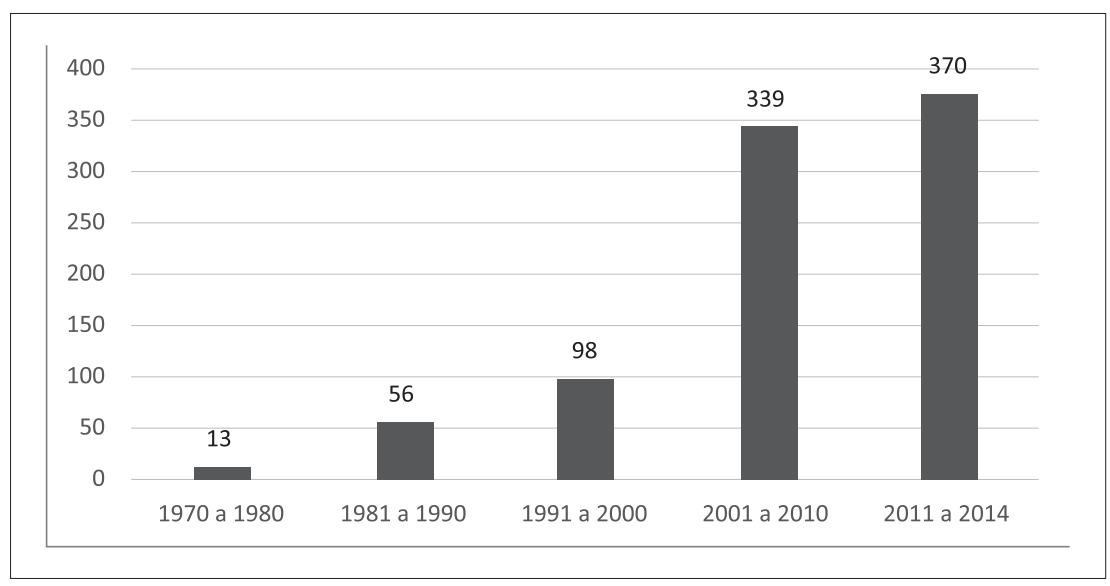

Fonte: Elaboração pelas autoras do artigo, com base nos artigos pesquisados.

Nota-se que, no período a partir de 1981, começa a aumentar exponencialmente o número de publicações, o que condiz com a perspectiva de Molina et al. (2012, p. 7), para quem o contexto do início dos anos de 1980 pode ser considerado marcante para a constituição do Ensino de História no Brasil como "importante campo de investigação", fortalecido pela expansão dos Programas de PósGraduação em História e em Educação [...] bem como da mobilização dos professores pesquisadores em torno de eventos organizados para discutir "caminhos da história ensinada", o que resultou, nos anos de 1990, na "afirmação da história escolar como objeto de pesquisa".

No século atual, está concentrada a grande maioria dos trabalhos $(81 \%)$, sendo que somente nos últimos quatro anos ultrapassou-se o número de artigos de toda a década anterior, que já foi elevado. Cabe lembrar que, nos últimos 25 anos, está concentrada também a maior criação de revistas, o que pode contribuir, mas não explica, sozinha, o aumento das publicações sobre o tema. Talvez aqui caiba uma futura reflexão sobre se o século XXI não constitui uma nova etapa na periodização a respeito do campo do Ensino de História em relação à proposta apresentada por Schmidt (2012).

Em relação aos temas abordados nos 876 artigos até agora identificados, o procedimento para classificação em subtemas que cada um abordava foi realizado da seguinte forma: uma leitura do título, do resumo e das palavras-chave e, quando não havia resumo, do 
texto integral. Após uma primeira classificação geral, foram definidos, então, 15 subtemas e retornou-se aos registros, classificando cada um em até três deles, sempre a partir do foco central de cada trabalho. Os subtemas estão distribuídos conforme apresentado no Gráfico 2.

GRÁFICO 2 - Ensino de História - Artigos por tema (1970-2014)

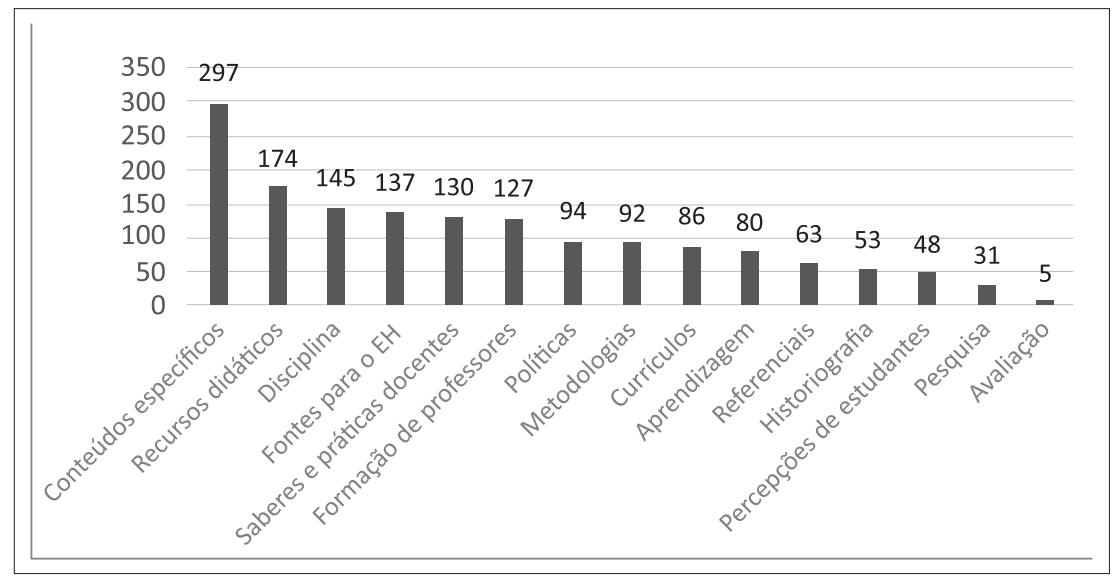

Fonte: Elaboração pelas autoras do artigo, com base nos artigos pesquisados.

Os seis primeiros temas concentram $64,7 \%$ de toda a produção identificada até o momento; e alguns, como Referenciais teóricos para o Ensino de História e Pesquisa, que refere-se ao campo e a discussões da produção sobre ele, estão presentes somente no fim do período, mais especificamente no século XXI. ${ }^{11}$

Em seguida, foram acessados os artigos na íntegra, para confirmar as temáticas preestabelecidas e levantar outros dados, como os referenciais ou os conceitos utilizados pelos autores do que deriva a sequência deste trabalho.

No tópico seguinte, serão abordados aqueles que trataram especificamente dos saberes e das práticas docentes, relacionados ao Ensino de História.

\section{SABERES E PRÁTICAS DOCENTES E ENSINO DE HISTÓRIA: 0 TEMA NOS ARTIGOS}

Como apresentado na Introdução, assumiu-se, para a classificação dos artigos na temática saberes e práticas docentes, uma acepção abrangente, não necessariamente conceitual, mas que envolve trabalhos com a preocupação de identificar e analisar o que e como os professores pensam e agem, e por que o fazem de determinada maneira, para desenvolver o Ensino de História. 
Toledo (2012) considera que, nas últimas décadas do século XX, ocorreram importantes mudanças na pesquisa da história acadêmica, em consonância com a perspectiva de Martins (2002) e Schmidt (2012):

Motivadas pelas tendências vivenciadas pelo panorama internacional, essas mudanças historiográficas trouxeram para a área do ensino de história revisões de interpretação da relação que se estabelece entre o saber histórico escolar e suas dimensões pedagógicas, particularmente aquelas ligadas à ideia tradicionalmente relacionada ao método ou metodologia de ensino. (TOLEDO, 2012, p. 227, grifos do autor)

Nesse processo, o diálogo entre referenciais da História e da Educação foi sendo construído, e a temática relativa aos saberes e às práticas docentes vai se consolidando como uma problematização relevante e necessária para a compreensão de como e por que a disciplina escolar História se configura(ou) ao longo do tempo, incluindo o tempo presente. De acordo com Monteiro (2007, p. 1213), "estudos e pesquisas no campo da educação têm contribuído para confirmar que a atuação dos professores implica mobilização de saberes, habilidades e competências, envolvendo subjetividades e apropriações". Para essa autora, a relação entre os professores e os saberes que mobilizam foi alvo de pesquisas desde a segunda metade do século XX, porém com mais força nos anos de 1980 e 1990 na América do Norte, com repercussões no Brasil (MONTEIRO, 2007, p. 173), traçando um histórico desse processo.

Tratando especificamente de saberes e práticas docentes, dos 876 artigos sobre Ensino de História identificados na pesquisa, 130 $(14,8 \%)$ o abordam ${ }^{12}$. Essa produção está distribuída, temporalmente, conforme apresentado no Gráfico 3.

GRÁFICO 3 - Saberes e práticas docentes - Ensino de História - artigos (1970-2014)

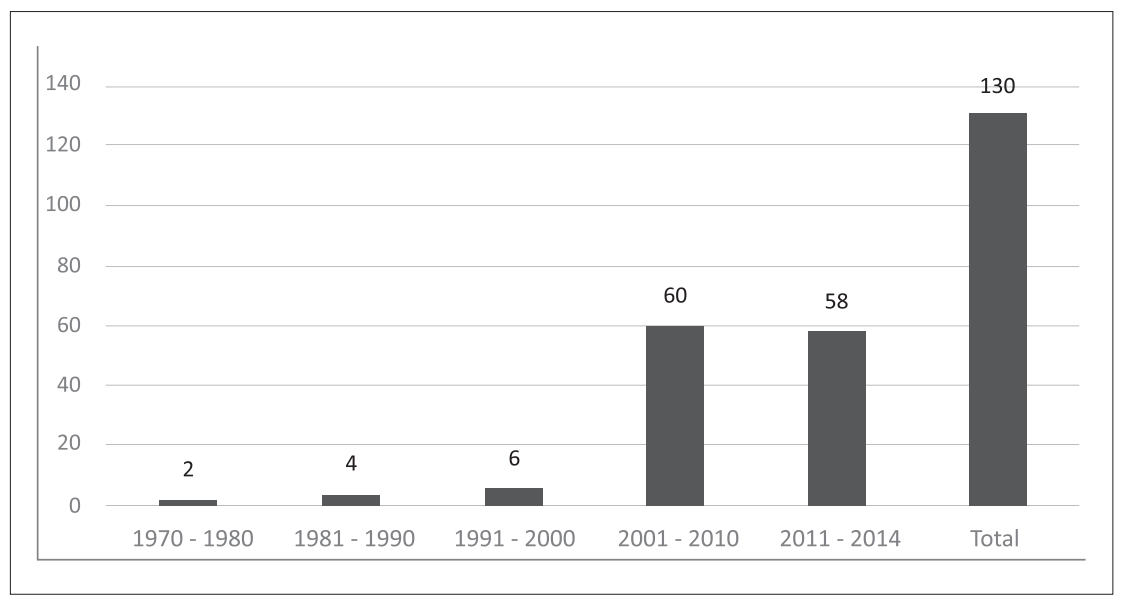

Fonte: Elaboração pelas autoras do artigo, com base nos artigos pesquisados. 
Em um primeiro momento, pode-se observar que os temas seguem a tendência geral da produção sobre Ensino de História com os artigos mais concentrados no século atual (90,7\%), o que confirma a perspectiva dos autores já abordados, que identificam vários elementos do contexto do fim do século XX como determinantes para a maior amplitude de pesquisas sobre o Ensino de História, sendo que a problematização dos saberes e das práticas nele envolvidos acompanha esse movimento.

O primeiro artigo identificado é de 1971 (MOTTA FILHO, 1971), e, mesmo com poucos trabalhos no decorrer do século XX, o tema vai se consolidando ao longo do tempo, como pode ser observado na Tabela 1.

TABELA 1 - Saberes e práticas docentes - Ensino de História distribuição temporal $(1970-2014)^{13}$

\begin{tabular}{|l|l|l|l|l|l|l|l|l|l|l|l|l|l|l|l|l|l|l|l|l|l|l|}
\hline $\mathbf{A}$ & 1 & 1 & 1 & 1 & 1 & 1 & 2 & 2 & 2 & 2 & 2 & 2 & 2 & 2 & 2 & 2 & 2 & 2 & 2 & 2 & 2 & $\mathbf{T}$ \\
$\mathbf{n}$ & 9 & 9 & 9 & 9 & 9 & 9 & 0 & 0 & 0 & 0 & 0 & 0 & 0 & 0 & 0 & 0 & 0 & 0 & 0 & 0 & 0 & $\mathbf{0}$ \\
$\mathbf{0}$ & 7 & 7 & 8 & 9 & 9 & 9 & 0 & 0 & 0 & 0 & 0 & 0 & 0 & 0 & 0 & 0 & 1 & 1 & 1 & 1 & 1 & $\mathbf{t}$ \\
$\mathbf{2}$ & 8 & 6 & 0 & 8 & 9 & 0 & 1 & 2 & 3 & 4 & 5 & 6 & 7 & 8 & 9 & 0 & 1 & 2 & 3 & 4 & $\mathbf{a}$ \\
$\mathbf{A}$ & & & & & & & & & & & & & & & & & & & & & & \\
$\mathbf{r}$ & 01 & 01 & 03 & 01 & 04 & 01 & 01 & 04 & 01 & 04 & 04 & 02 & 08 & 08 & 09 & 12 & 08 & 08 & 26 & 13 & 11 & $\mathbf{1 3 0}$ \\
t. & & & & & & & & & & & & & & & & & & & & & \\
\hline
\end{tabular}

Fonte: Elaboração pelos autores deste artigo.

Enquanto o tema aparece de forma fragmentada em somente quatro anos antes de 1998, a partir daí, houve ao menos um trabalho em cada ano, sendo que o volume foi crescente, até um auge, em 2012, com $20 \%$ deles. Aquele é um ano intrigante para esta produção, que segue a tendência geral dos trabalhos sobre Ensino de História. Nele estão concentrados 80 dos 876 artigos identificados na pesquisa mais ampla; é o ano com maior número deles, possivelmente pela convergência de vários dossiês publicados, evidenciando o crescente destaque do tema, do número de pesquisadores e interessados, e de consistência da produção sobre ele, uma vez que foram aprovados por revistas reconhecidas e bem-avaliadas no Qualis, ou seja, aprovados em periódicos com sérios critérios de avaliação dos trabalhos a eles apresentados.

Como pode ser observado na Tabela 1 , a discussão sobre saberes e práticas docentes relativos ao Ensino de História acompanha a consolidação do campo do Ensino de História. Além disso, Monteiro (2007, p. 23) destaca que, em meados do século XX, a racionalidade técnica era dominante, ocorrendo uma mudança a partir do fim dos 
anos de 1970 e nos anos de 1980, com as contribuições da nova sociologia da educação e das teorias críticas do currículo, com uma renovação no campo da didática, passando-se de "uma perspectiva referenciada à racionalidade técnica dominante" em direção à busca de abordagens que pudessem "dar conta da complexidade das mediações envolvidas nos processos de ensino-aprendizagem", o que pode ter contribuído para o aumento de trabalhos sobre esse tema, desde 1998.

Entre as possibilidades de análise da área de Educação que Monteiro identifica está a linha de pesquisa que preocupa-se com as atividades docentes, "buscando investigar os saberes envolvidos e mobilizados em sua realização e que, melhor conhecidos, podem contribuir para a sua qualificação através da formação e do fortalecimento da identidade profissional" (MONTEIRO, 2007, p. 23). Sob essa perspectiva, buscou-se analisar os artigos para averiguar quais as preocupações dos autores e, consequentemente, como pretendiam contribuir para a reflexão sobre o tema.

Em relação aos objetivos dos artigos, buscou-se classificá- $\operatorname{los}^{14} \mathrm{em}$ :

- Saberes: o que ou como os professores pensam, e por que pensam ou entendem o ensino de História de determinada maneira; e

- Práticas: o que ou como os professores fazem, e por que desenvolvem determinadas ações ou encaminhamentos no Ensino de História.

Conforme Monteiro (2007, p. 227), os saberes constituem um eixo abrangente:

[...] podemos ver que os saberes emergem como eixo que articula as várias instâncias e sujeitos envolvidos. Saberes ensinados, o que implica considerar o contexto escolar como instância de produção de saberes próprios; saberes mobilizados, o que implica considerar a dimensão da prática, da ação e, portanto, reconhecer diferentes apropriações.

Dessa forma, para fins de análise, a classificação realizada buscou identificar a ênfase ou a preocupação principal dos autores, como apresentado na Tabela 2.

Os trabalhos preocupam-se em averiguar o que e como os professores pensam e entendem o Ensino de História (48,37\%) - não necessariamente a partir do conceito de saberes, como será abordado no Gráfico 4 -, ou o que e como o desenvolvem, por meio de suas práticas (40,65\%). Em consequência, a compreensão dos porquês dessa forma de pensar $(4,88 \%)$ ou de agir $(6,1 \%)$ fica em segundo plano. 
TABELA 2 - Saberes e práticas docentes - Ensino de História: objetivos principais dos artigos, por áreas de trajetórias dos autores (1970-2014)

\begin{tabular}{|l|c|c|c|c|c|}
\hline & Saberes & Saberes & Práticas & Práticas & - \\
\hline Área & 0 que/como & Por que & 0 que/como & Por que & Totais \\
\hline Educação & 38 & 01 & 34 & 03 & 76 \\
\hline História & 26 & 04 & 24 & 03 & 57 \\
\hline Educação e História & 32 & 06 & 27 & 04 & 69 \\
\hline Outras & 02 & 0 & 02 & 0 & 04 \\
\hline Não consta & 21 & 01 & 13 & 05 & 40 \\
\hline Totais & 119 & 12 & 100 & 15 & 246 \\
\hline
\end{tabular}

Fonte: Elaboração pelos autores deste artigo.

Há um equilíbrio entre os que abordam Saberes e os que tratam das Práticas, sendo que o total das referências indica que a maioria dos trabalhos abordam ambos, pois mesclam a compreensão dos professores sobre determinada questão com a forma como lidam com ela em sala de aula. Também são semelhantes a distribuição de o que/como e de por que entre Saberes e Práticas.

Abaixo, seguem alguns exemplos dessas categorias, para ilustrar a classificação dos trabalhos. Não há exemplos perfeitos, pois a leitura foi feita no artigo na íntegra, para se chegar à classificação realizada. Os objetivos escolhidos são retirados dos resumos.

\section{I - Saberes - o que/como}

O objetivo da pesquisa realizada foi o de analisar como a reforma de ensino de 1971, conhecida como a Lei n. 5692, atingiu o ensino de História paranaense, mais precisamente na cidade de Curitiba e Região Metropolitana, levando em conta, além das fontes escritas - tais como documentos oficiais e currículo -, os testemunhos orais de alguns professores de Estudos Sociais da época. (MARTINS, 2001, p. 197)

Este trabalho apresenta resultados de uma pesquisa que teve como foco concepções docentes acerca das relações entre educação e direitos humanos, na qual procurou-se identificar as possíveis relações existentes entre o tema da educação em direitos humanos e o ensino de história, na direção de estabelecer alianças entre esses dois campos. (ARAUJO, 2013, p. 67)

\section{II - Práticas - o que/como}

Este artigo tem como objetivo investigar como os professores PDE do ensino fundamental e médio da rede pública de Londrina e de outras cidades da região norte do Paraná utilizam o livro didático de história em sua prática em sala de aula. (CUNHA, 2010, p. 196)

Embora tenha havido artigos classificados somente em Saberes ou em Práticas e, nelas, em o que ou como, não houve artigo 
classificado unicamente como Práticas ou Saberes - por quê. Ou seja, todos ${ }^{15}$ os que abordaram de alguma forma os porquês das formas de pensar ou de fazer dos docentes desenvolveram essa reflexão juntamente ou a partir dos o que e como eles pensam ou fazem, como os exemplos abaixo.

III - Práticas - o que ou como, e por quê

As reflexões que se seguem resultam de uma pesquisa realizada durante o ano de 1995 com vinte e cinco professores de História (graduados em História, licenciatura curta) que, na época, atuavam nas escolas de rede pública e na iniciativa particular de ensino de Uberlândia/MG. As reflexões aqui desenvolvidas incidem sobre as justificativas destes professores para o emprego dos livros didáticos bem como sobre a análise que fazem desses mesmos livros. (LIMA, 1998, p. 195)

IV - Saberes - o que ou como, e por quê

[...] este estudo considera a questão da formação teórica do professor entendida, aqui, como a formação recebida no ensino superior e a possibilidade de embasamento desta formação para a prática pedagógica. (BALDIN, 1986, p. 18)

Este artigo tem como objetivo investigar a profissão do educador de História, através de sua identidade narrativa. Nesta pesquisa, buscamos relacionar a formação inicial do educador com a percepção que tem da docência. (CUNHA; CARDÔZO, 2011, p. 141)

Ainda, houve trabalhos classificados em Saberes e em Práticas - o que/como, por exemplo:

Apresenta os resultados parciais de uma investigação [...] cujo problema de pesquisa trata das concepções de identidade histórica presentes nas aulas de História Local de professoras do $3^{\circ}$ ano do Ensino Fundamental, de uma escola da rede municipal de Campo Largo-PR. (GERMINARI; BUCKENKO, 2012, p. 125)

O estudo focaliza a implementação das leis na formação inicial e os impactos nos saberes e práticas dos professores de História na Educação Básica. (CEREZER; GUIMARÃES, 2013, p. 181)

\section{Ainda, alguns classificados em Saberes por que e Práticas como, por exemplo:}

O objetivo deste texto é discutir como professores, em processo de formação, têm selecionado 'novas linguagens' para o Ensino de História [...] procurouse acompanhar as escolhas feitas como parte do processo de construção da identidade docente e dos saberes históricos escolares. (OLIVEIRA, 2012, p. 262)

E, finalmente, o único caso classificado como Saberes e Práticas - por quê:

Este trabalho reflete sobre a prática pedagógica em história face às transformações ocorridas no âmbito das referências teóricas que informam aquela prática. 
[...] A conclusão permitiu ver o ensino de história como uma região em transição problemática: renovam-se as referências conceituais na produção do conhecimento histórico, mas esta renovação não repercute adequadamente sobre o ensino da disciplina. (BRANCO, 2008, p. 232)

Os exemplos acima citados permitem vislumbrar a diversidade de preocupações e objetivos dos autores, bem como a dificuldade e a necessária subjetividade na aplicação da classificação proposta, evidenciando que outros pesquisadores, com outros olhares, poderiam organizá-los de forma distinta da aqui assumida. Nesse caso, esperase que, com a divulgação dessa pesquisa, possa-se contribuir para o desenvolvimento de outras análises e problematizações sobre o tema.

Embora "o que" e "como" constituam problematizações da maioria dos trabalhos identificados nesta pesquisa, relativos a saberes e práticas docentes em Ensino de História, as análises parecem focar um diagnóstico, em geral, a partir de entrevistas ou observações de aulas, mas que não envolvem uma reflexão dos autores ou mesmo dos sujeitos das pesquisas, acerca de por que e como desenvolveram aquela forma de pensar ou de agir.

Nesse sentido, parece confirmar-se e estender-se até a produção acadêmica de 2014 a conclusão de Monteiro (2007, p. 25): "como os professores mobilizam os saberes que dominam para explicar os diferentes temas dos conteúdos, estabelecer relações de causalidade, esclarecer dúvidas, selecionar exemplos, analogias, realizar demonstrações têm ficado ausentes nas pesquisas".

O desafio da realização de estudos acerca do porquê determinadas formas de pensar e agir são desenvolvidas pelos docentes no Ensino de História ainda é, portanto, questão a ser enfrentada nesse campo.

Dos trabalhos identificados como voltados à compreensão dos saberes e das práticas docentes, a grande maioria (114) trata de questões contemporâneas à sua publicação, e somente dezesseis trazem uma problematização histórica, configurando uma característica de grande preocupação relativa a dilemas do tempo presente. Isso pode estar relacionado ao tipo de fontes possíveis para a problematização dos saberes e das práticas à medida que o tempo é recuado, mas os autores que investem na história do Ensino de História utilizam-se de depoimentos (quando período mais próximo), relatórios de estágio e outras produções escritas (cadernos, livros e livros didáticos), por exemplo, como fontes, o que pode ser ilustrado pelos trabalhos de Ricci (1998) e de Oliveira (2012).

Por outro lado, aqueles que se voltam a questões contemporâneas utilizam como fonte, prioritariamente, observações, 
depoimentos, questionários e documentos escritos diversos, como livros didáticos, relatórios de estágio, obras acadêmicas, legislação, entre outros. Por exemplo, os trabalhos de Garcia (1978), de Zimmermann e Réchia (1999), de Marques (2009), de Felipe e Teruya (2012) e de Silva e Backers (2014).

Sobre os conceitos utilizados pelos autores nos artigos, buscouse identificar a referência principal, ou seja, o autor ou o conceito que foi de fato operacionalizado como referencial teórico, relativos aos saberes e às práticas docentes abordados, não enfocando aqueles que eram apenas mencionados nos trabalhos. Dessa forma, obtiveram-se as seguintes indicações conceituais, conforme apresentado no Gráfico 4.

GRÁFICO 4 - Saberes e práticas docentes - Ensino de História - principais conceitos

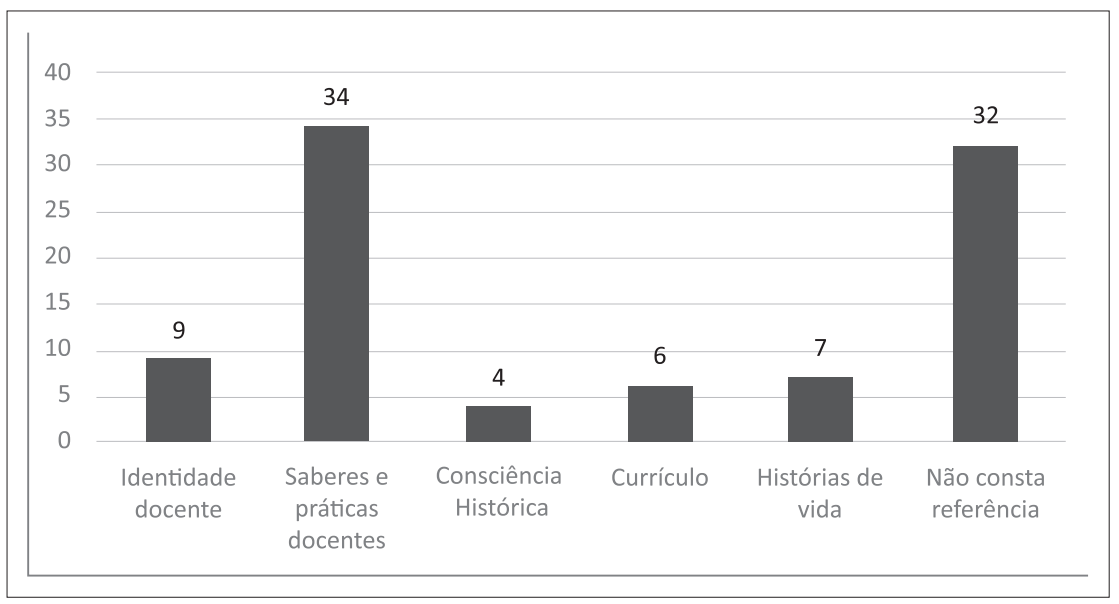

Fonte: Elaboração pelas autoras do artigo, com base nos artigos pesquisados.

Vale destacar o número de artigos que tratam do tema abordado sem operacionalizar ou evidenciar um conceito ou autor de referência específicos sobre eles, mencionando saberes ou práticas docentes, sem defini-los: 35,16\%. Porém ressalta-se que isso não significa necessariamente ausência de alguma fundamentação ou referencial - embora isso também ocorra.

Em muitos casos, os autores que apresentam conceitos relativos ao "sobre o que" estão investigando os saberes e as práticas, ou seja, se se trata de averiguar como os docentes abordam a História Regional, é esse o conceito operacionalizado. Por outro lado, tratandose de conceitos específicos dos saberes docentes e sua ausência em mais de um terço dos artigos identificados, pode-se identificar o que Shulman (2007) constata: "a ausência de perspectivas de abordagem 
nas pesquisas educacionais sobre o que o professor sabe do ponto de vista dos conteúdos ensinados constitui o "missing paradigm" (SHULMAN, 1986, p. $6^{16}$ citado por MONTEIRO, 2007, p. 25). Nesses trabalhos, o saber e a prática docente são abordados, porém como meio para a compreensão de um outro fim, relacionado ao tema central do artigo, por exemplo, a história regional acima citada, ou do livro didático. Por outro lado, essa situação pode evidenciar um pressuposto de senso comum acerca dessa questão, que pode refletir na qualidade e na profundidade de sua abordagem. ${ }^{17}$

No Gráfico 5, são apresentados os autores mais utilizados como referências nos 130 artigos.

Monteiro (2007, p. 23-24) ressalta os principais autores relacionados às pesquisas sobre saberes e práticas docentes, sendo possível identificar alguns deles, presentes no Gráfico 5, ou ao menos com os quais eles dialogam:

- Conhecimento escolar: Isambert-Jamati; Chevallard; Develay; Forquin; Moreira; Lopes; Goodson; Chervel; e Gabriel;

- Saber docente: Tardif, Lessar e Lahaye; Tardif; e Tardif e Lessard; Shulman; Lelis;

- Conhecimento-na-ação e professor reflexivo: Schön;

- Saberes práticos e competências: Perrenoud;

- Práxis reflexiva: Nóvoa;

- Identidade profissional de professores: Lüdke e Moreira.

GRÁFICO 5 - Saberes e práticas docentes - Ensino de História principais autores de referência

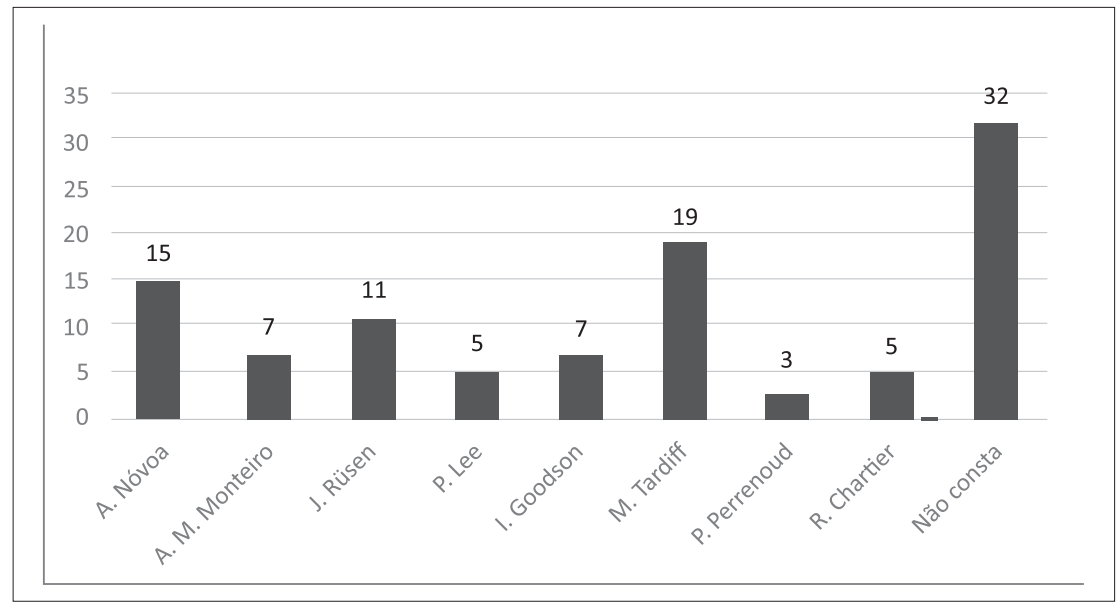

Fonte: Elaboração pelas autoras deste artigo, com base nos artigos pesquisados. 
Ainda, no Gráfico 5, pode-se destacar Ana Maria Monteiro como referência para sete trabalhos, configurando-a como referência, no Brasil, sobre a temática saberes e práticas docentes em Ensino de História; e a presença de Roger Chartier, utilizado principalmente para análise de representações de professores acerca de determinadas questões.

Jorn Rüsen e Peter Lee aparecem como autores de referência no Gráfico 12, mas com somente um conceito relacionado à Educação Histórica, no Gráfico 11. Como referências da Educação Histórica, estão mais presentes a partir de 2005, porém deles são utilizados vários conceitos, como didática da História (três menções), aprendizagem histórica (uma), pensamento histórico (uma), literacia histórica (uma) e código disciplinar de história (uma).

A presença de autores relacionados à Educação Histórica nos 130 artigos que abordam saberes e práticas docentes ocorre a partir de 2006, com o trabalho de Barca (2006), estando presente nos anos de 2008, 2011 e 2013 com uma menção, e, em 2007 e 2010, com duas, havendo um pico em 2012 com oito menções, e quatro, em 2014.

Nesses trabalhos, autores como Isabel Barca, Peter Lee, Jörn Rüsen, Maria Auxiliadora Schmidt, Marlene Cainelli, Luis Fernando Cerri, entre outros, são mencionados e, muitas vezes, utilizados conjuntamente com referências específicas de saberes e práticas docentes, como Maurice Tardif, Antonio Nóvoa, Ivor Goodson e Ana Maria Monteiro.

A entrada desse novo referencial no Brasil é detectada por Evangelista e Triches (2006) no Diretório de Grupos de Pesquisa do CNPq a partir de 2005, o que é compatível com o início de presença desse referencial nas produções aqui abordadas.

Observa-se que esse movimento pode significar o início de tensões internas ou lutas de representações no campo Ensino de História - a ser ainda melhor investigado a partir dos 876 artigos identificados na pesquisa -, mas que já permite identificar um indício na disputa por legitimidade do novo referencial que se estabelece. Dos 21 artigos que trazem autores, obras ou conceitos da Educação Histórica, somente dez indicam Ensino de História como palavrachave, mesmo assim, conjuntamente com outras, relacionadas à Educação Histórica. Nos outros casos, preferem indicar a própria Educação Histórica ou os conceitos dela derivados, como consciência histórica ou literacia histórica, como palavras-chave. Essa escolha significa que esses autores reconhecem que tais expressões e conceitos serão utilizados, preferencialmente, quando outros forem buscar seus artigos; ou, ainda, pretendem demarcar claramente, nesse espaço, a sua vinculação à Educação Histórica, distinguindo-se daqueles que indicam - e daqueles que buscam - Ensino de História. 
Barca (2001) já situava essa perspectiva teórica com o trabalho Educação Histórica: uma nova área de investigação, que parece um pouco mais sutil, indicando o início dessas discussões nos anos de 1970, na Inglaterra, nos Estados Unidos e no Canadá, a partir da questão da cognição histórica.

Por sua vez, Schmidt e Barca (2008, p. 11) afirmam:

Atualmente pode-se constatar um grande desenvolvimento e especialização de investigações no domínio específico do ensino de História. Neste sentido, é possível se falar da existência de diferentes comunidades de pesquisadores em vários países do mundo, cujo objeto de estudo é o ensino e a aprendizagem da História. [...] Dentro desta comunidade internacional, um grupo de pesquisadores fez opção pelo trabalho na área denominada Educação Histórica.

Embora as expressões campo de conhecimento e área de conhecimento ou de investigação possam ser comumente utilizadas como sinônimas, é interessante observar que, no trecho acima, o Ensino de História é referido como objeto, e a Educação Histórica, como área, o que poderia sugerir um status próprio para essa última. Porém, em uma leitura mais atenta, as autoras acabam por situar a Educação Histórica como uma das perspectivas possíveis para a abordagem do Ensino de História.

Essas questões e olhares a respeito de a Educação Histórica ser uma possibilidade teórica dentro do campo Ensino de História, ou se ela constitui um campo próprio, em suas distintas nuances, fazem parte da luta de representações presente: "Qualquer que seja o campo, ele é objeto de luta tanto em sua representação, quanto em sua realidade" (BOURDIEU, 2004, p. 29).

Apesar de essa questão conceitual e de referências estar aqui relacionada somente aos artigos relativos a saberes e práticas docentes em Ensino de História, a hipótese que se assume é de que essa luta de representações está presente em todas as demais temáticas, ou seja, no campo Ensino de História como um todo, o que será melhor fundamentado no decorrer da análise dos demais artigos envolvidos na pesquisa. Segundo Chartier (1990, p. 17):

As lutas de representações têm tanta importância como as lutas econômicas para compreender os mecanismos pelos quais um grupo impõe, ou tenta impor, a sua concepção do mundo social, os valores que são os seus, e o seu domínio. Ocuparse dos conflitos de classificações ou de delimitações não é, portanto, afastar-se do social [...], muito pelo contrário, consiste em localizar os pontos de afrontamento mais decisivos quanto menos imediatamente materiais.

Assim podem ser compreendidas as distintas referências e a presença da Educação Histórica e de conceitos a elas relacionados 
nas palavras-chave dos artigos, em mais da metade deles não sendo utilizada a expressão Ensino de História. Porém, embora chame a atenção a ausência dela em mais da metade dos trabalhos com referencial da Educação Histórica e aqui seja assumido que essa pode ser uma escolha no sentido de estabelecer a legitimidade e evidenciar o novo referencial, é importante destacar que a expressão Ensino de História não está presente, como palavra-chave, praticamente na metade dos 130 artigos aqui analisados.

Somente 68 deles trazem-na como palavra-chave, embora outros tragam História e ensino como palavras separadas. Porém, naqueles que não se referem à Educação Histórica, dada a diversidade de objetos e referenciais, não foi possível identificar uma posição de possível demarcação de terreno, uma vez que as palavras-chave se referem especificamente ao objeto abordado, como, por exemplo, formação de professores (29), História (19), professores (14) e currículo (13). Como pode ser observado, não há necessariamente a presença de conceitos ou referenciais teóricos explícitos neles. Por isso assume-se que, embora a proporção do uso da palavrachave Ensino de História nos artigos com referencial da Educação Histórica seja equivalente à do restante dos artigos, nela a opção tem uma intencionalidade específica.

Apesar dessa luta de representações, configura-se nessa produção a compreensão de Monteiro et al. (2014, p. 9) sobre a utilização de referenciais da História e da Educação, na busca de compreensão e análise dos desafios epistemológicos presentes na contemporaneidade, razão pela qual confirma-se, aqui, que a pesquisa em Ensino de História se trata de um "lugar de fronteira em que se recontextualizam e se hibridizam diferentes perspectivas teóricas e abordagens oriundas das duas áreas" (MONTEIRO et al., 2014, p. 9).

Esse entendimento é compartilhado por Garcia (2009, p. 80), que afirma o Ensino de História como "um campo que agrega pesquisadores de duas ciências de referência que devem orientar as decisões de investigação quanto à dimensão epistemológica e, por conseguinte, metodológica".

\section{CONSIDERACְÕES FINAIS}

A partir dos resultados aqui apresentados, pode-se afirmar que, no campo mais amplo Ensino de História, na acepção de Bourdieu, configura-se um diálogo com produções e conceitos relativos aos saberes e às práticas docentes, derivados da Educação, e que passam a 
permear e a orientar questões e problemas. Porém, também é possível identificar que parte dessas publicações, derivadas de perguntas sobre o que, como e - em menor escala - por que os professores de História pensam, compreendem e agem de determinadas formas, carecem de um aprofundamento conceitual sobre os saberes e as práticas, o que poderia contribuir para a melhor compreensão de como tais saberes e práticas são constituídos e mobilizados, e, consequentemente, sobre por que e como neles se configuram permanências e práticas, no Ensino de História.

Além disso, há disputas nele que, por sua vez, podem contribuir para a inserção de novas temáticas e problematizações, à medida que se consolidam novos referenciais e perspectivas de investigação.

Buscou-se compreender essa configuração em relação ao campo Ensino de História de forma mais ampla, com o panorama geral relativo aos 95 periódicos pesquisados e aos 876 artigos identificados, como as principais instituições de trajetória dos autores. Nele, talvez a principal constatação e proposição, que deverá ser melhor desenvolvida e fundamentada com a exploração mais minuciosa de todos os artigos identificados na pesquisa, é de que o século XXI pode ser compreendido como período de consolidação da produção desse campo, avançando na periodização anteriormente proposta por Schmidt (2012).

Tratando especificamente dos saberes e das práticas docentes em Ensino de História, há a caracterização geral da produção sobre essa temática, composta por 130 artigos. Nele, destaca-se a maior concentração dos trabalhos no século XXI, em consonância com a produção geral do campo Ensino de História e também com a consolidação da produção relativa aos saberes e às práticas docentes no Brasil, nos anos finais da década de 1990.

Ficou evidenciado que a grande permanência da produção acerca dos saberes e das práticas docentes em Ensino de História é a investigação acerca de o que e como os professores pensam e ensinam, em contraposição a um número muito menor de trabalhos $(10,97 \%)$ que se dedicam a estudar os porquês dessas formas de pensar e agir dos docentes. Configura-se, assim, uma lacuna importante, na qual cabe investir mais, na pesquisa do campo.

Nos 130 artigos, vale ressaltar o número significativo de trabalhos que não trazem referenciais nem operacionalizam conceitos relativos a saberes e práticas docentes $(24,6 \%)$, que, em geral, quando utilizam tais expressões, fazem-no como substantivos, e não como conceitos, o que também indica a necessidade de pesquisadores que se dedicam a essa questão, avançar no diálogo e no uso de referenciais específicos, oriundos do campo educacional, a fim de incrementarem e melhor problematizarem seus trabalhos. Isso porque a mudança de 
substantivo para conceito traz questões, nuances e contribuições mais elaboradas sobre a temática, que podem contribuir significativamente para aprofundar e aperfeiçoar tais estudos.

Quanto aos trabalhos que trazem conceitos pertinentes ou relacionados a saberes e práticas docentes, os principais autores são aqueles presentes nesse tipo de pesquisa no campo educacional, destacando-se Maurice Tardif, Antonio Nóvoa, Ivor Goodson e Ana Maria Monteiro. Essa última se configura como a única brasileira presente nas principais menções a autores e, assim, pode ser compreendida como referência para a temática, em especial - mas não somente - quando aplicada ao Ensino de História.

A partir de 2006, começam a aparecer trabalhos com referências da Educação Histórica, por vezes em diálogo com os autores específicos de saberes e práticas docentes, caracterizando um gradativo fortalecimento dessa perspectiva analítica no campo Ensino de História, que pode significar tensões e lutas de representações sobre o próprio campo, como pode ser observado em relação à escolha das palavras-chave. Por outro lado, essa nova perspectiva teórica pode vir a contribuir com novas problematizações para a temática.

Esta pesquisa, como toda investigação acadêmica, tem seus limites, inclusive relacionados ao tempo para seu desenvolvimento. Muitas das questões aqui apontadas e anunciadas deverão ser melhor exploradas e aprofundadas à medida que os capítulos forem configurados em publicações específicas, tanto no que tange especificamente aos saberes e às práticas docentes, quanto ao Ensino de História de forma mais ampla.

Outros limites são os estabelecidos pelos critérios utilizados na seleção das fontes. Dessa forma, ficaram de fora da pesquisa periódicos que não estão em duas das áreas selecionadas (Educação, História e Ensino), nas categorias A1 a B3 do Qualis; livros e capítulos de livros; Anais de eventos acadêmicos e dissertações e teses. Os limites podem configurar-se, porém, em possíveis outras pesquisas a serem desenvolvidas e em novas contribuições para a compreensão da constituição e dos caminhos trilhados pelo campo Ensino de História.

\section{FONTES CITADAS}

ARAUJO, Cinthia M. Alianças entre o PNEDH e o ensino de história: concepções docentes sobre as relações entre educação e direitos humanos. Educação [impresso], Porto Alegre, v. 36, n. 1, p. 67-73, jan./abr. 2013.

BALDIN, Nelma. Realidade do ensino de História: a formação teórica, base para a prática 
pedagógica? Perspectiva, Florianópolis-SC: UFSC, n. 6, p. 18-38, jan./jun. 1986.

BARCA, Isabel. Literacia e consciência histórica. Educar em Revista, Curitiba, número especial, p. 96-112, 2006.

BRANCO, Edwar A. C. Desvendando a Prática Pedagógica em História: o professor frente à história e seu ensino. Educação, Porto Alegre, v. 31, n. 3, p. 232-238, set./dez. 2008.

CEREZER, Osvaldo M.; GUIMARÃES, Selva. O estudo da História e cultura afrobrasileira e indígena na educação básica: dificuldades e possibilidades. Revista Eletrônica Documento/Monumento, Cuiabá-MT, n. 9, p. 181-196, 2013.

CUNHA, Jorge L.; CARDÔZO, Lisliane S. Ensino de História e formação de professores: narrativas de educadores. Educar em Revista, Curitiba, n. 42, p. 141-162, out./dez. 2011.

CUNHA, Maria de F. Aprendi com a prática e continuo aprendendo: os professores de história e o uso do livro didático na região norte do Paraná. Patrimônio e Memória, AssisSP: UNESP: FCLAs: CEDAP, v. 6, n. 2, p. 196-216, dez. 2010.

FELIPE, Delton A.; TERUYA, Teresa K. Narrativas de docentes sobre a obrigatoriedade do ensino da História e Cultura Afro-Brasileira. Educação, Porto Alegre, v. 35, n. 2, p. 208216, maio/ago. 2012.

GARCIA, Consuelo. Desempenho de professores em áreas urbanas - Estudos Sociais e Ciências. Educar em Revista, Curitiba, n. 2, p. 111-148, 1978.

GERMINARI, Geyso; BUCKENKO, Gerson. História local e identidade: um estudo de caso na perspectiva da Educação Histórica. História \& Ensino, Londrina, v. 18, n. 2, p. 125142, jul./dez. 2012.

LIMA, Sandra C. F. O livro didático de História: Instrumento de Trabalho ou Autoridade "Científica"? História \& Perspectivas, Uberlândia, n. 18-19, p. 195-206, 1998.

MARQUES, Luiz A. S. Histórias de vida: narrativas do cotidiano como suporte ao ensino de História e Geografia nas séries iniciais do ensino fundamental. Cadernos de Educação, Pelotas-RS: UFPel, n. 32, p. 211-227, jan./abr. 2009.

MARTINS, Cláudia R. K. O ensino de História no Paraná, na década de setenta: práticas de professores. Educar, Curitiba, n. 17, p. 197-213, 2001.

MOLINA, Ana H. et al (Org.) Apresentação. In: CERRI, Luis Fernando (Org.). Ensino de História e Educação: olhares em convergência. Ponta Grossa: Ed. UEPG, 2012. v. 2, p. 7-9.

MOTTA FILHO, Cândido. O ensino de História. Revista do Instituto Histórico e Geographico Brazileiro, Rio de Janeiro, n. 290, p. 156-162, 1971.

OLIVEIRA, Nucia A. S. "Novas" e "diferentes" linguagens e o ensino de História: construindo significados para a formação de professores. EntreVer, Florianópolis, v. 2, n. 2, p. 262-277, jan./jun. 2012.

RICCI, Cláudia S. Quando os discursos não se encontram: imaginário do professor de história e a reforma curricular dos anos 80 em São Paulo. Revista Brasileira de História, v. 18, n. 36 , p. $61-88,1998$.

SILVA, José B. A.; BACKES, José L. De sólidas para líquidas, de líquidas para sólidas: as concepções de professores de História sobre os processos de construção das identidades negras. Poiésis, Tubarão-SC, v. 8, n. 14, p. 496- 514, jul./dez. 2014

ZIMMERMANN, Josiane; RÉCHIA, Karen C. Prática de ensino de História: considerações preliminares. Perspectiva, Florianópolis, v. 11, número especial, p. 6S-11, jan./jun. 1999. 


\section{REFERÊNCIAS}

BARCA, Isabel. Educação Histórica: uma nova área de investigação. História - Revista da Faculdade de Letras, Porto-Portugal, III série, v. 2, p. 13-21, 2001.

BARRETO, Elba S. S.; PINTO, Regina P. (Coord.) Avaliação na Educação Básica (19901998). Brasília-DF: MEC/Inep/Comped, 2001. (Série Estado do Conhecimento, n. 4).

BOURDIEU, Pierre. Os usos sociais da ciência: por uma sociologia clínica do campo científico. São Paulo: Ed. Unesp, 2004.

BOURDIEU, Pierre. O campo científico. In: ORTIZ, Renato (Org.). Pierre Bourdieu: Sociologia. São Paulo: Ática, 1983. p. 122-155.

CIRANI, Claudia B. S.; CAMPANARIO, Milton A.; SILVA, Heloisa H. M. A evolução do ensino da pós-graduação senso estrito no Brasil: análise exploratória e proposições para pesquisa. Avaliação, Campinas, v. 20, n. 1, p. 163-187, 2015.

CHARTIER, Roger. A história cultural. Entre práticas e representações. Lisboa: Difel, 1990. CORRÊA, Ana M. M. Prefácio. In: DE LUCA, Tania R. A revista do Brasil: um diagnóstico para a (N)ação. São Paulo: FUNDUNESP, 1999.

EVANGELISTA, Olinda; TRICHES, Jocemara. Ensino de História, Didática de História, Educação Histórica: alguns dados de pesquisa (2000-2005). Educar em Revista, número especial, p. 1-21, 2006.

GARCIA, Tânia M. F. B. Relações entre ensino e aprendizagem histórica: desafios para a pesquisa em Educação Histórica. In: SCHMIDT, Maria A.; BARCA, Isabel (Org.). Aprender História: perspectivas da Educação Histórica. Ijuí: Ed. Unijuí, 2009. p. 77-116.

MARTINS, Maria C. A história prescrita e disciplinada nos currículos escolares: quem legitima esses saberes? Bragança Paulista: EDUSF, 2002.

MONTEIRO, Ana M. Professores de História: entre saberes e práticas. Rio de Janeiro: Mauad X, 2007.

MONTEIRO, Ana M. et al. (Org.). Apresentação. In: MONTEIRO, Ana M. et al Pesquisa em Ensino de História: entre desafios epistemológicos e apostas políticas. Rio de Janeiro: Mauad X: Faperj, 2014. p. 7-13.

PROST, Antoine. As palavras. In: RÉMOND, René (Org.). Por uma história política. Rio de Janeiro: Editora UFRJ, 1996. p. 295-330.

SCHMIDT, Maria A.; BARCA, Isabel (Org.). Aprender História: perspectivas da Educação Histórica. Ijuí: Ed. Unijuí, 2009.

SCHMIDT, Maria A. M. S. História do ensino de História no Brasil: uma proposta de periodização. Revista de História da Educação - RHE, Porto Alegre, v. 16, n. 37, p. 73-91, maio/ago., 2012. Disponível em: < http://seer.ufrgs.br/index.php/asphe/article/ view/24245/pdf>. Acesso em: 7 set. 2015.

SHULMAN, L. Those who understand: knowledge growth in teaching. Educational Researcher, Washington, v. 15, n. 2, p. 4-14, 1986.

SIRINELLI, Jean-François. Os intelectuais. In: RÉMOND, René (Org.). Por uma história política. Rio de Janeiro: Editora UFRJ, 1996. p. 231-270.

TOLEDO, Maria A. L. T. História escolar e escrita da história: por uma historiografia do ensino de história. In: MOLINA, Ana H. et al. (Org.). Ensino de História e Educação: olhares em convergência. Ponta Grossa: Ed. UEPG, 2012. v. 2, p. 225-248. 


\section{NOTAS}

1 Corpus é entendido como um conjunto de documentos a ser submetido aos procedimentos analíticos.

2 Disponível em: <http://qualis.capes.gov.br/webqualis/principal.seam\#>. Acesso em: 10 abr. 2014.

${ }^{3}$ Por exemplo, foram excluídos os periódicos Alfa: Revista de Linguistica (UNESP, online); Caderno Brasileiro de Ensino de Física; Psicologia Argumento (PUC-PR, online).

${ }^{4}$ Até o momento, foram localizados cerca de $98,5 \%$ dos volumes de periódicos necessários. Os que faltam, em geral, são números iniciais de periódicos que não estão disponíveis online e cujos volumes impressos ainda não foram localizados nas bibliotecas pesquisadas ou, ainda, não se obteve retorno das Secretarias das revistas.

${ }^{5}$ Muitos periódicos constam na listagem do Qualis com dois ISSN, geralmente um online e um para impressos, mas são a mesma publicação, com os mesmos trabalhos; estes foram unidos na pesquisa pelo título do periódico. Também, optou-se por incluir no levantamento dois periódicos que estão somente em uma área, mas que tinham elevado número de artigos sobre o tema Ensino de História: Ensino em Re-vista e EntreVer - Revista das Licenciaturas, com, respectivamente, 22 e 16 artigos.

${ }^{6}$ Dessa forma, artigos que abordem outra questão e que somente mencionem o Ensino de História não são selecionados, por exemplo, se tratar de formação de professores de forma genérica e, em algum momento, ilustrar uma situação ou argumento com um exemplo com o Ensino de História.

${ }^{7}$ Embora na pesquisa online no acervo da USP tenham sido encontrados alguns dos volumes ainda pendentes, no dia da ida à instituição, embora outras instâncias administrativas USP estivessem funcionando quanto ao atendimento, inclusive a Biblioteca da Faculdade de Educação, a Biblioteca da Faculdade de Filosofia, Letras, e Ciências Humanas estava fechada, devido à paralisação de seus funcionários, o que inviabilizou a pesquisa no seu acervo.

${ }^{8}$ Destaca-se que, em relação ao vínculo, algumas revistas são publicadas em parceria, por exemplo, de uma Associação com uma Universidade, o que levou a 101 registros desse tipo, para os 95 títulos pesquisados.

${ }^{9}$ Optou-se por quantificar em volumes em vez de números, devido a haver fases de várias revistas em que foram publicados mais de um número no mesmo volume, por exemplo, v. 3 n. 1/2 e, nesse caso, não seria correto dizer que há um artigo em dois números da revista.

${ }^{10}$ Ainda falta localizar alguns exemplares de periódicos; estima-se que em torno de 1,5\% do total integral de todos os periódicos. É uma estimativa por não haver históricos que informem quantos volumes e números foram publicados em cada ano que ainda está em aberto. Consequentemente, após a localização destes, os dados aqui apresentados deverão ser alterados. Embora considere-se que o que foi localizado até o momento seja uma amostragem significativa, ainda estão sendo realizados esforços para localizar os volumes faltantes.

${ }^{11}$ No caso do subtema Historiografia, que em geral tem artigos que discutem o diálogo das produções ou do Ensino de História com a produção historiográfica (com exceção de um artigo), está presente a partir do fim dos anos de 1990. Por outro lado, todos os demais, com maior ou menor frequência, são abordados ao menos desde os anos de 1980. Essas questões deverão ser abordadas em trabalhos subsequentes, em suas especificidades.

${ }^{12}$ Essa indicação de número de artigos que abordam o tema Saberes e práticas docentes foi feita com base na leitura dos resumos dos artigos. $\mathrm{Na}$ continuidade do desenvolvimento 
da pesquisa, outros trabalhos, que inicialmente não haviam sido classificados nesse tema, poderão vir a sê-lo, à medida que forem lidos na íntegra. Destaca-se que foram encontrados muitos outros trabalhos sobre esse tema, mas somente foram selecionados para a pesquisa aqueles que se referiam especificamente ao Ensino de História.

13 Os anos que não constam na Tabela 1 são aqueles em que não foram encontrados artigos sobre o tema.

${ }^{14}$ Destaca-se que essa classificação foi uma das mais subjetivas da pesquisa, porque deriva do olhar e da compreensão da pesquisadora sobre os textos, que podem ser suscetíveis de outras perspectivas e leituras. Por vezes, a fronteira entre o que e como pensam(vam) e fazem(iam) de determinada forma e da explicação de por que isso acontecia é muito tênue, optando-se, assim, por classificar o artigo na categoria entendida como a ênfase dos autores, embora tenha havido alguns casos em que as duas dimensões foram abordadas explicitamente. Nesses casos, foram indicadas as duas categorias.

${ }^{15}$ Com exceção de Branco (2008), apresentado como último exemplo dessa sequência.

${ }^{16}$ SHULMAN, Lee. Those who understand: knowledge growth in teaching. Educational Researcher, v. 15, n. 2, Washington, p. 4-14, feb.1986.

${ }^{17}$ No artigo citado, Shulman (1986, p. 6) alerta para o fato de que a investigação sobre o conhecimento dos professores sobre a matéria ensinada configurava um paradigma ausente nas pesquisas educacionais. No Brasil, Monteiro $(2007,2014)$ tem desenvolvido um programa de pesquisas sobre os saberes produzidos pelos professores nas aulas de história para contextualizar, problematizar, conceituar, explicar os conteúdos abordados. Operando com contribuições da teoria da História - em especial aquelas sobre narrativa histórica, do campo do currículo e da didática, essa investigação tem possibilitado avançar na compreensão dos saberes e das práticas em perspectiva articulada que explicita essa relação.

Submetido: 04/11/2015

Aprovado: 12/06/2016

Contato:

Nadia G. Gonçalves

UFPR - Setor de Educação (DTPEN)

Rua General Carneiro, 460, Edifício D.Pedro I, $5^{\circ}$ andar Curitiba|PR |Brasil

CEP 80.060-150 